
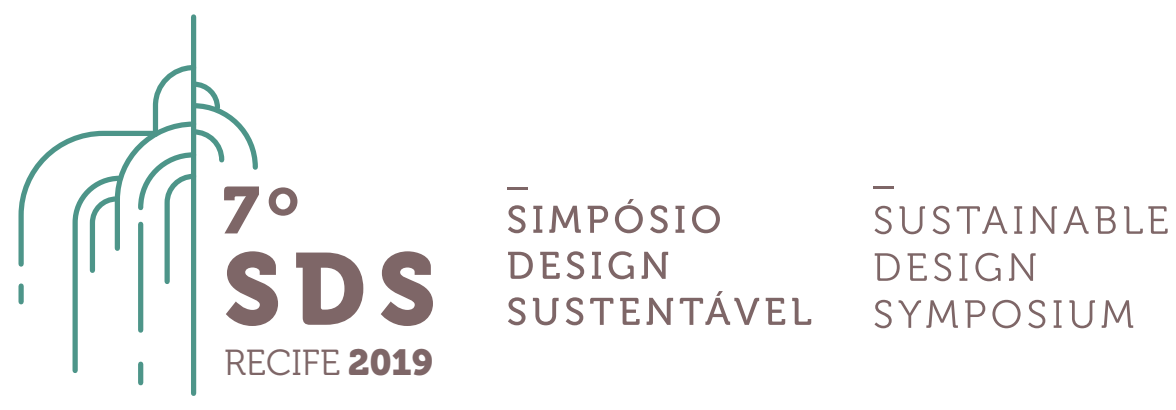

\title{
Design, antropologia e colaboração: engajamentos no bairro de Santa Teresa no Rio de Janeiro
}

\author{
María Cristina Ibarra \\ Universidade Federal de Pernambuco, Departamento de Design, mcibarra.ufpe@gmail.com
}

\begin{abstract}
Resumo. O objetivo deste artigo é analisar meu trabalho e experiência, como designer e pesquisadora, com o Coletivo Santa sem Violência (CSSV) sob a perspectiva interdisciplinar do campo de Design Anthropology (DA). Começo com uma introdução ao campo e seus argumentos, continuo com a apresentação do CSSV, suas reuniões, ações e membros, e termino com uma análise do trabalho com o coletivo, à luz dos argumentos do campo de DA. Este campo propõe, entre outras coisas, o reconhecimento das habilidades das pessoas e a exploração colaborativa de possibilidades para o(s) futuro(s). Uma das intenções do Coletivo era, precisamente, explorar possibilidades que combatessem a violência no bairro. Como designer $e$ pesquisadora, pretendi praticar um design que correspondesse aos interesses do coletivo, valorizasse as habilidades dos seus integrantes $e$ explorasse colaborativamente alternativas para o futuro.
\end{abstract}

Palavras-chave. Design. Antropologia. Colaboração. Sustentabilidade Social. Praticantes Habilidosos. Futuros possíveis.

\section{Introdução ao campo de Design Anthropology (DA)}

Design Anthropology (DA) ${ }^{1}$ é um campo acadêmico que conjuga elementos do design e da antropologia (OTTO, SMITH, 2013). A partir de uma abordagem transdisciplinar, DA se permite reformular métodos estabelecidos do design e da antropologia, possibilitando novas abordagens e misturas metodológicas (KJ/ERSGAARD et al, 2016). Para Otto e Smith (2013), este campo vem amadurecendo como uma subdisciplina separada com seus próprios conceitos, métodos, práticas de pesquisa e praticantes. Em suma, com seu próprio estilo distinto e práticas de produção de conhecimento.

\footnotetext{
${ }^{1}$ Optei pelo uso do termo Design Anthropology, com grafia em inglês, porque assim ele é usado na bibliografia pesquisada. Em português não há ainda uma discussão aprofundada sobre o que seria a melhor tradução para o termo, uma vez que não se trata de uma antropologia do design, nem de um design antropológico. Ou seja, uma palavra não adjetiva a outra, assim como um dos campos de conhecimento não restringe o outro. Considera-se que existe uma conjunção dos dois saberes que cria um terceiro espaço.
} 
Para estes autores, o estilo distinto de fazer antropologia presente em DA se evidencia no grande número de antropólogos trabalhando no e com design, teses de doutorado sobre o tema, conferências e publicações e cursos em universidades. Os autores esperam que o campo de DA contribua com a antropologia de modo mais geral e que haja uma crítica ao design para construir uma prática mais humana e descolonizada por meio da adoção de atributos da antropologia.

Otto e Smith (2013) explicam que as novidades de DA estão relacionadas com as formas intervencionistas de trabalho de campo e design que trabalham por meio de ciclos iterativos de reflexão e ação, e empregam métodos e ferramentas como feedbacks de vídeo, cenários, mock-ups, props, provótipos ${ }^{2}$ - e protótipos, interações tangíveis, e várias formas de jogos e performances. Igualmente, DA também compreende várias formas de colaboração interdisciplinar dentro e fora do estúdio de design. O campo de DA está caracterizado por um uso particular da teoria que visa gerar conceitos e novas estruturas ou perspectivas.

Para Gunn e Donovan (2012) há diferentes maneiras de entender e praticar a relação do design e da antropologia:

dA - A contribuição teórica provêm da antropologia. Neste caso, o design segue a antropologia em seus entendimentos teóricos ou a antropologia utiliza o design como objeto de estudo.

Da - O trabalho de campos dos antropólogos é colocado ao serviço das práticas de design.

DA - As disciplinas do design e da antropologia estão ligadas em uma convergência de esforços, aprendendo uma da outra (HALSE, 2008 apud GUNN; DONOVAN, 2012).

Esta última abordagem é a tratada nas quatro coletâneas mais representativas na área que são: Design Anthropology. Object culture in the 21st Century, editada por Alison Clarke (2011), Design and anthropology (Anthropological Studies of Creativity and Perception), editada por Wendy Gunn e Jared Donovan (2012), Design Anthropology: Theory and Practice editada por Wendy Gunn, Ton Otto, Rachel Smith (2013) e o livro Design Anthropological Futures, editado por Mette Gislev Kjaersgaard, Joachim Halse, Rachel Charlotte Smith, Kasper Tang Vangkilde, Thomas Binder e Ton Otto (2016).

Na primeira coletânea, Design Anthropology: Object culture in the 21st Century, editada por Alison Clarke (2011), mostra-se uma preocupação com a materialidade, porém não desde o ponto de vista do consumo e de métodos racionalistas, mas a partir da confluência com o social. Segundo Clarke (2011), os designers agora são mais propensos a se engajar na pesquisa social, tanto como na produção de coisas. O livro faz alusão às relações entre design e antropologia nos anos 1970 e 1980, perguntando-se como se constitui essa relação atualmente. A coletânea mostra como a antropologia pode ajudar a desenvolver uma sensibilidade cultural, que, segundo a editora, pode contribuir para construir um design que responde socialmente. Vale ressaltar que este livro nasce de contribuições independentes de autores interessados na relação design/antropologia.

Esta primeira coletânea foi reeditada em 2017, adicionando um artigo do antropólogo colombiano Arturo Escobar ${ }^{3}$ titulado 'Stirring the Anthropological Imagination'. Esta contribuição de Escobar fez com que o título da coletânea fosse redefinido para: Design Anthropology - Object Cultures in Transition. No artigo, o autor propõe um exercício de imaginação de transição para o vale

\footnotetext{
2 O termo 'provótipo' (ou provotypes) surge da conjunção entre a criação de protótipos e a provocação de conversas e reflexões. Para Mogensen (1992), os provótipos pretendem criar soluções "provocando discrepâncias na prática concreta e cotidiana para suscitar o que normalmente é considerado como garantido" (MOGENSEN, 1992, p.22, tradução nossa).

${ }_{3}^{3}$ Arturo Escobar é um destacado antropólogo colombiano, professor da Universidade da Carolina do Norte, em Chapel Hill, Estados Unidos. Entre seus interesses de pesquisa se destacam a ecologia política, a antropologia do desenvolvimento e movimentos sociais na América Latina. Nos últimos 25 anos, tem colaborado com organizações afro-colombianas no Pacífico e no Estado do Norte do Cauca, Colômbia (ESCOBAR, 2016).
} 
geográfico do rio Cauca na Colômbia. Este texto surge a partir do livro 'Diseño y Autonomía' (2016) em que o autor expõe a noção de design autônomo em sintonia como o design para a transição.

A segunda coletânea, Design and anthropology (Anthropological Studies of Creativity and Perception), editada por Wendy Gunn e Jared Donovan (2012), surge de uma série de seminários, disciplinas para estudantes de doutorado e colaborações entre diferentes universidades da Europa. O livro, assim como a primeira coletânea, também mostra abordagens fora da resolução de problemas. Os autores e editores estão preocupados na aproximação entre usar e produzir (using and producing), projetar e usar (designing and using) e pessoas e coisas. Os editores explicam que, no que se refere a relação entre usar e produzir, na coletânea, o destacado antropólogo britânico, Tim Ingold (2012), introduz o conceito de 'praticantes habilidosos', mostrando que os usuários não são passivos e que nas suas práticas há apropriação e habilidade.

A terceira coletânea, Design Anthropology: Theory and Practice editada por Wendy Gunn, Ton Otto, Rachel Smith (2013), identifica a ligação do design e da antropologia como um campo com um estilo próprio. Os editores esclarecem que parte dos artigos presentes nesta coletânea nasceram de um painel realizado em agosto de 2010 na 11 o Biennial European Association of Social Anthropologist Conference, na Universidade Nacional da Irlanda, Maynooth. O painel se chamou Design Anthropology: Intertwining different Timelines, Scales and Movements. Este livro, segundo os autores, abre um espaço para pensar a relação entre teoria e prática. Eles explicam que os colaboradores deste volume tem mostrado como a teoria gerada através da prática pode se envolver nos processos de design. Igualmente, neste livro, há uma preocupação em direcionar a antropologia à ação, diferente da descrição. Na minha perspectiva, neste livro propõe-se a antropologia como uma prática intencionalmente intervencionista e o design como uma prática interpretativa.

A quarta coletânea, Design Anthropological Futures, editada por Mette Gislev Kjaersgaard, Joachim Halse, Rachel Charlotte Smith, Kasper Tang Vangkilde, Thomas Binder e Ton Otto (2016), "é uma culminação material da Rede de Pesquisa para Design Anthropology ${ }^{4}$ [...] o objetivo da rede tem sido reunir pesquisadores da Dinamarca e internacionalmente para identificar potenciais e desafios no campo de design anthropology" (SMITH et al, 2016, p. xiv). Desde minha perspectiva, esta coletânea está preocupada tanto com o futuro do campo de DA, como com a criação de futuros. No livro, os autores insistem que o futuro é plural e que não é um lugar vazio. Os autores propõem perspectivas alternativas para as noções de singularidade, linearidade, novidade e localidade.

Em suma, nas quatro coletâneas mostra-se um reconhecimento por parte do design das habilidades das pessoas. Na primeira, no estudo dos objetos vernaculares como uma crítica à cultura consumista, na segunda, na análise das habilidades dos chamados usuários nas práticas do dia-a-dia e na ressignificação do uso dos objetos. Na terceira, na preocupação dos praticantes de DA em trabalhar em equipes multidisciplinares e em processos de cocriação. Na quarta, na ideia de que a inovação não surge de centros privilegiados, senão na cotidianidade.

Igualmente, nas quatro coletâneas há uma preocupação em escapar da separação tradicional de coisas e humanos ou do material e o imaterial. Essa tradição torna os objetos em passivos e os humanos em ativos e impede perceber as relações que há entre ambos.

Por outro lado, nas quatro coletâneas há um interesse em ampliar o horizonte temporal do design e da antropologia. Há uma crítica ao design moderno e a seus conceitos de inovação e

\footnotetext{
${ }^{4}$ A Rede de Pesquisa para Design Anthropology (The Research Network for Design Anthropology) foi criada em 2014, na Dinamarca, por professores de The Royal Danish Academy of Fines Arts (KADK), da Aarhus University, e da University of Southern Denmark. Esta rede está formada por pesquisadores do mundo inteiro e explora modos emergentes de conhecimento relacionados ao campo. Para mais informação sobre a rede ver site:

https://kadk.dk/en/research-network-design-anthropology.
} 
universalização. Nestes livros, mostra-se que os praticantes de DA estão preocupados com os fenômenos emergentes e com a relação do passado, presente e futuro.

Por último, na terceira e na quarta coletânea, os autores mostram as práticas de DA como constituindo um campo distinto de conhecimento. Vale ressaltar que entende-se o adjetivo 'distinto' não como um campo claro e definido, senão como um campo reconhecível, diferente dos demais. Com este trabalho, percebe-se DA como um campo em contínua transformação, em movimento, um campo com vida, aberto à mudança e as variações.

A seguir, apresento o Coletivo Santa Sem Violência, um grupo de moradores de um bairro de classe média do Rio de Janeiro, com o qual trabalhei durante aproximadamente um ano. No meu trabalho com o coletivo, procurei levar à prática e analisar alguns pressupostos do campo de DA.

\section{Coletivo Santa sem Violência (CSSV)}

O Coletivo Santa Sem Violência (CSSV) foi um grupo de moradores do bairro de Santa Teresa (Rio de Janeiro) que atuou desde maio de 2016 até metade de 2017 para combater a violência na área. Isto, através da criação de espaços de discussão e diálogo entre moradores e da implementação de táticas preventivas, como a idealização e organização de ações culturais que ativassem as ruas e praças e pressionassem o poder público, e a criação de uma proposta de um sistema de monitoramento de segurança por meio de câmeras espalhadas pelo bairro. Este grupo era autogestionado e se sustentava economicamente através da doação de dinheiro e materiais por parte de membros, moradores e comerciantes e através da venda de adesivos com o logo do coletivo.

\subsection{Membros do Coletivo Santa Sem Violência}

Todos os membros do coletivo eram moradores do bairro, uns mais engajados que outros. Os mais comprometidos com o coletivo eram os membros do Núcleo, depois seguiam os assistentes assíduos às reuniões e eventos, os membros de grupos nas redes sociais - WhatsApp e Facebook - que só participavam de forma virtual, e por último, os participantes esporádicos ou circunstanciais, como por exemplo, as crianças da Escola Monte Alegre que se envolveram com a pintura de escadarias do Largo do Curvelo (Figura 1).

O Núcleo estava composto por 10 pessoas: Angélica Gomes (atriz e professora de circo, 47 anos naquele momento), Candice Abreu (atriz e professora, 35), Cláudio Fantinato (músico, padeiro, marceneiro e biólogo, 39), Ingrid Reis (empreendedora criativa, 42), Leonardo Farias (empresário, 36), Liliana Jaeger (empresária e publicitária, 36), Natty Fraga (auditora, 35), Roosivelt Pinheiro (artista plástico, 51), Sabrina Mesquita (fotógrafa, 34) e eu (Maria Cristina, designer, 28). Este pequeno grupo surgiu sem um planejamento prévio, da necessidade de ter um conjunto de pessoas ágeis e comprometidas com o Coletivo, que pudessem dar andamento às atividades.

As funções do núcleo, surgidas espontaneamente, eram: organizar as reuniões, divulgá-las entre os amigos e vizinhos, coletar fundos, organizar e planejar atividades nas ruas, comprar materiais, fazer ponte com outras instituições ou iniciativas, etc.

\subsection{Reuniões}

No coletivo havia reuniões do Núcleo e as chamadas reuniões gerais, aquelas abertas à comunidade. De forma geral, as reuniões do núcleo se intercalavam com as reuniões gerais, de 
maneira que o Núcleo pudesse concretizar ideias e organizar antecipadamente os encontros que contariam com maior número de participantes. Usualmente, as reuniões com o núcleo eram realizadas em lugares privados pelo temor de alguns membros de virar alvo de criminosos. Já as reuniões gerais aconteciam em lugares públicos como o Largo das Neves e o Parque das Ruínas (Figura 2) e, algumas vezes, em lugares privados conhecidos pelos moradores e com capacidade para receber grande número de pessoas como o Centro Cultural Laurinda Lobos e o Mercado das Pulgas no Largo dos Guimarães.

As principais atividades realizadas nas reuniões gerais eram: comentar casos recentes de violência no bairro, pensar e planejar ações públicas e/ou estratégias para combatê-los, conhecer ideias e pensamentos dos participantes e atribuir responsabilidades. As reuniões tanto do Núcleo quanto as gerais duravam normalmente duas horas e eram feitas, em média, duas por mês.

À diferença da primeira reunião, as reuniões não eram estruturadas, nem tinham oficinas engenhosamente formatadas, eram informais e abertas ao que estivesse acontecendo no bairro naquele momento. Desde a primeira reunião e depois de cada uma delas, Angélica fez atas com o objetivo de comunicar aos ausentes o que tinha acontecido em cada encontro e também levar um registro. Estas atas foram publicadas na página e no grupo do Facebook do coletivo.

Figura 1 - Pessoas e organizações relacionados ao Coletivo Santa Sem Violência

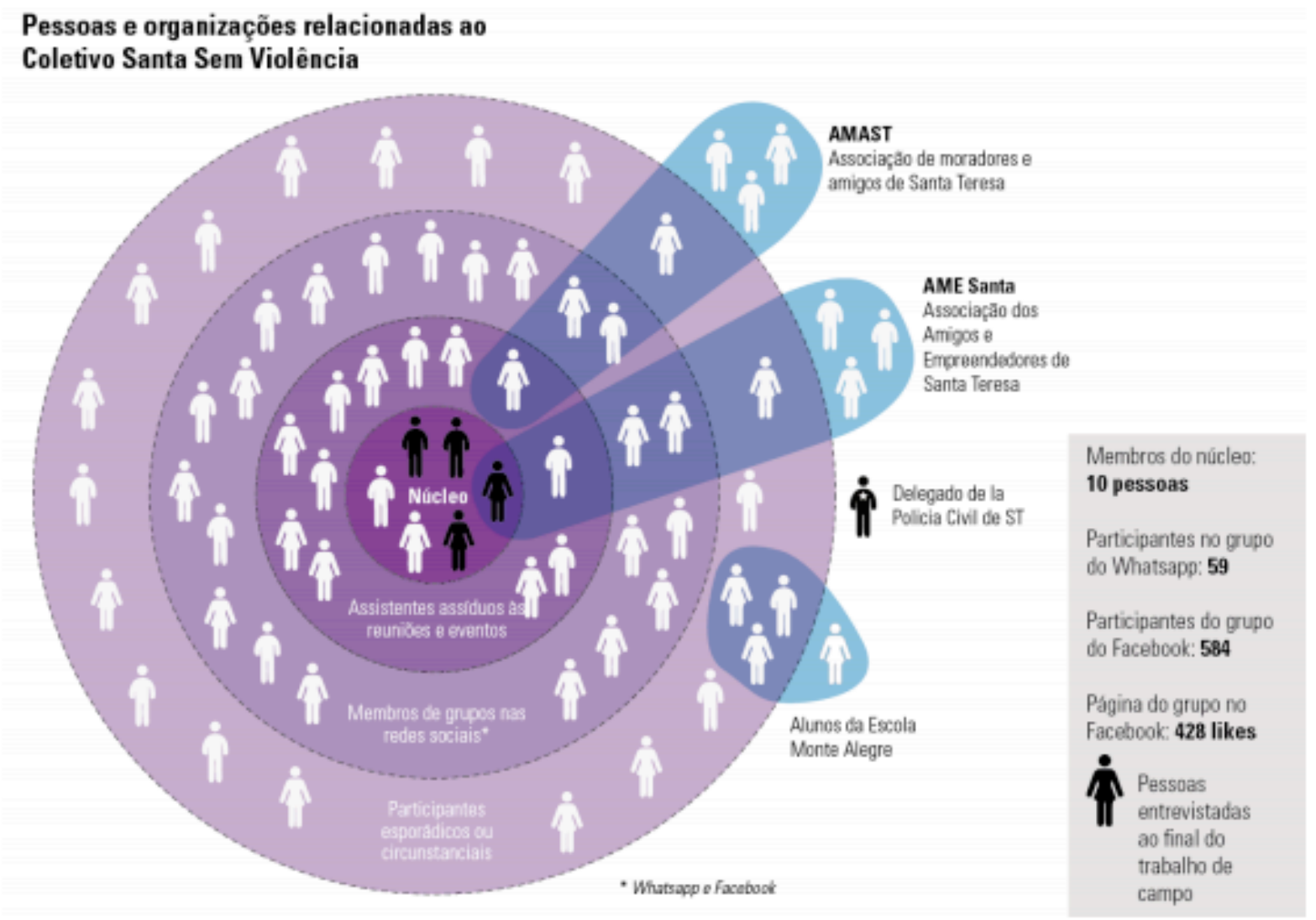

Fonte: Elaborado pel@ autor@baseada em SERAVALLI; ERIKSEN; HILLGREN, 2017 
Figura 2 - Reunião realizada no Parque das Ruínas - Setembro de 2016.
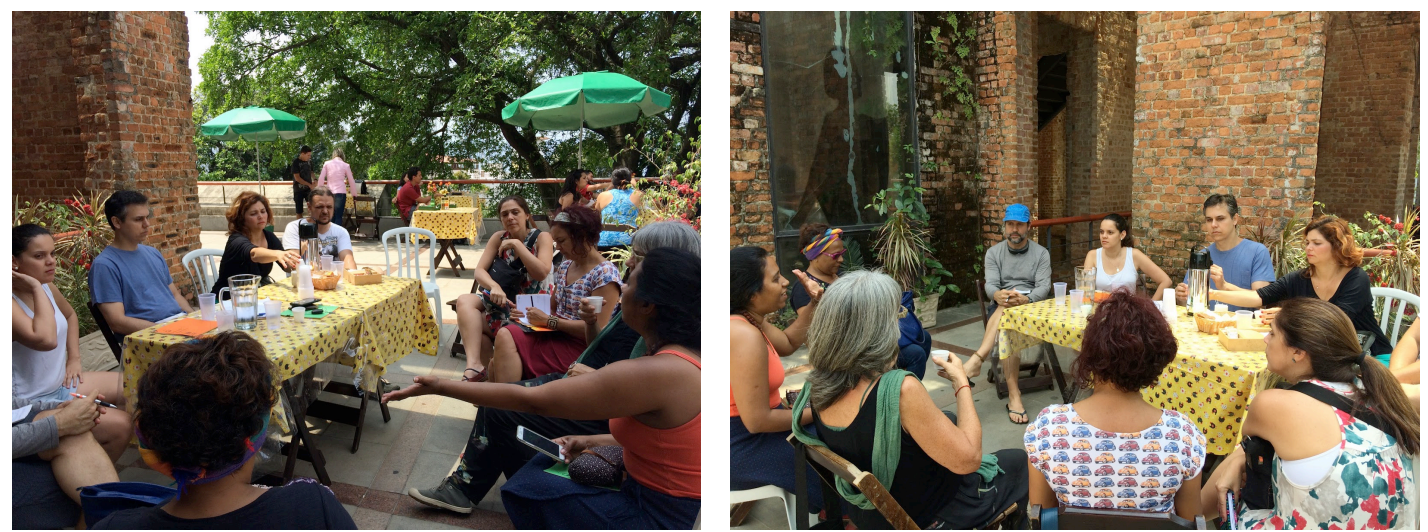

Fonte: Fotos da autora (2016)

\subsubsection{Manifestação no Largo dos Guimarães}

Dentre as ações realizadas pelo CSSV, a manifestação no Largo dos Guimarães foi uma das mais importantes. Ela aconteceu no dia 11 de junho de 2016, sábado de manhã no no ponto mais importante do bairro, que reúne visitantes e moradores. Por meio de um evento no Facebook, folhetos espalhados nas redes sociais e convites feitos de forma verbal, o coletivo chamou palhaços, bailarinos, artistas, músicos e, em geral, todos os moradores do bairro para participar. Desde o primeiro encontro no Largo das Neves, outros encontros foram realizados para organizar essa atividade, na qual foram planejados cartazes e estênceis, para colá-los nas paredes próximas à praça. A meu ver, o objetivo da manifestação era chamar a atenção das autoridades e comunicar aos moradores e visitantes a seriedade da onda de violência que tinha tomado conta do bairro.

Cerca de quarenta pessoas compareceram, incluindo crianças e adultos. Eu pude reconhecer alguns assistentes à primeira reunião no Largo das Neves, porém eu estava mais familiarizada com os moradores que participaram das reuniões antes da manifestação. A maioria dos participantes eram amigos de Angélica, de seu trabalho como atriz e circense e do bairro. Parecia que alguns deles eram amigos de longa data.

Muitas atividades foram realizadas por diferentes grupos em diferentes momentos e lugares. Em frente à estação de bonde, havia um grande grupo fazendo estênceis, pôsteres e camisetas com o logo do coletivo; nos arredores, como em alguns restaurantes, no cinema e no Mercado das Pulgas, outro grupo colava alguns cartazes nas paredes; duas palhaças leram repetidamente através de um megafone uma espécie de manifesto composto pelo Coletivo reivindicando o direito de se locomover com segurança na vizinhança; uma paródia de uma canção famosa foi escrita e cantada para falar sobre violência, uma performance chamada "Santa de cabeça para baixo" foi feita no meio da rua, alguns estrangeiros participaram com discursos em espanhol e inglês, um grupo tirava fotos e vídeos, e um curto discurso contra a violência foi falado por um representante da Associação de Moradores do bairro, AMAST. Havia muito entusiasmo no ar (Figura 3).

Naquela época, vi essa manifestação como uma indicação do forte desejo do grupo de ser ouvido por outros moradores, pela polícia, pela mídia e pelos turistas. Ela tinha um tom forte de demanda e insatisfação, mas também um senso de comunidade e fraternidade na forma como exigia uma vizinhança ativa e a união de residentes de diferentes partes que usaram sua criatividade e habilidades para expressar o que vivenciavam. 
Os membros do coletivo expressaram que, apesar do fato de que apenas alguns moradores participaram da manifestação, em comparação com a quantidade que estávamos esperando, eles tinham ficado satisfeitos com o resultado. Leonardo agradeceu a Angélica por sua iniciativa e ela incentivou o resto do grupo a continuar trabalhando juntos. Ela também mencionou que, desde aquela época, poderíamos chamar esse trabalho de "nossa iniciativa" e que a manifestação era um momento para nos tornarmos visíveis no bairro. Claudio disse que foi uma atividade muito positiva e, Ingrid e eu expressamos o quanto apreciamos a congregação de pessoas. Em uma conversa online, definimos a data para a próxima reunião. Na minha perspectiva, neste momento o grupo foi se formando.

Além da manifestação, o CSSV realizou outras atividades como o apoio ao show do grupo Pirarucú Psicodélico e a pintura de escadarias no Largo do Curvelo em Santa Teresa. Particularmente, meu trabalho com o coletivo teve duração de um ano aproximadamente.

Figura 3 - Manifestação no Largo dos Guimarães

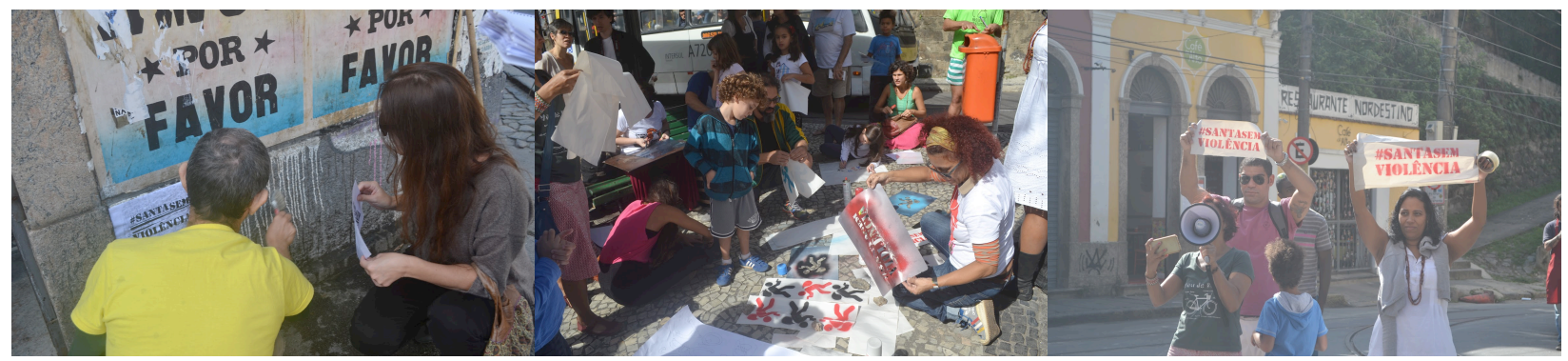

Fonte: Foto da autora (2016)

\section{Design, antropologia e colaboração}

A seguir, analiso minha experiência e prática com o Coletivo Santa Sem Violência no bairro de Santa Teresa à luz da literatura apresentada na primeira seção deste artigo.

No CSSV eu era mais uma moradora. Esta condição me possibilitou fazer parte do coletivo de uma maneira genuína. Além de moradora, eu era pesquisadora e designer. Uma das minhas inquietações de pesquisa antes de começar a trabalhar com o coletivo era: como o design pode contribuir para que os frequentadores das praças e ruas sejam considerados 'praticantes habilidosos'? Me instigava o fato de que as pessoas que frequentavam o espaço público não fossem apenas receptores de algo que foi planejado com antecedência por outras pessoas. Eu queria explorar como os não-designers se engajavam na criação do espaço público. Descobrir a iniciativa do coletivo Santa sem Violência foi como encontrar um tesouro, não para ser admirado, e, sim, para me juntar a eles ou, como o antropólogo Tim Ingold (2012a) sugere, 'se juntar à reunião'. O grupo se propunha a pensar, enquanto moradores, como podíamos mudar a situação que o bairro estava passando. Naquela primeira reunião no Largo das Neves, o convite de Angélica foi para pensarmos coletivamente em alternativas à realidade que estávamos vivendo. Como designer, como eu podia contribuir para isso? A antropologia poderia contribuir?

Me aproximando ao universo da antropologia, encontrei autores que acreditavam nas habilidades dos não-designers. Como apontei anteriormente, na coletânea Design and anthropology (Anthropological Studies of Creativity and Perception), editada por Wendy Gunn e Jared Donovan (2012), uma das preocupações dos autores é a aproximação entre usar e produzir (using and producing). Em um dos artigos desta coletânea, Ingold (2012) propõe a noção de 'praticantes 
habilidosos'. Com este conceito, o autor defende a ideia de que durante os processos de uso, os consumidores não são passivos, pelo contrário, nas suas práticas há apropriação e habilidade.

Os praticantes habilidosos envolvidos em processos de fazer (making), segundo Wendy Gunn (2012), criam formas através de fluxos e movimentos prospectivos. Citando Ingold, ela explica que a prática habilidosa não significa imposição, ao contrário, ela depende do entendimento das propriedades dos materiais. O fazer é fluido e improvisatório e está sempre em processo de transformação. Ela argumenta que o praticante habilidoso ajusta continuamente seus movimentos em resposta à tarefa ou ao trabalho que vai surgindo. Um dos principais pontos da prática habilidosa é trabalhar com incertezas, isso implica aprender à medida em que se avança, e não antes. Ou seja, as ações não podem ser entendidas como uma série de instruções ou regras, pois estas não se constituem antes, senão durante o processo. As maneiras de trabalhar são aprendidas através da prática.

Ingold (2012) afirma que "cada objeto de design coloca armadilhas ao apresentar um problema na forma daquilo que parece ser a solução" (INGOLD, 2012, p.20, tradução nossa). Assim, os designers estabelecem as regras do jogo, ou seja, através dos objetos projetados eles determinam a relação das pessoas com as coisas. O autor coloca como exemplo o ato de tomar café da manhã. Ele afirma que "manipular colheres, sentar-se numa cadeira e comer à mesa são habilidades corporais que levam anos para serem adquiridas" (idem, p. 21, tradução nossa). Os objetos de design dificultam as tarefas cotidianas de alguma forma e quem os utiliza precisa encontrar modos de lidar com essas regras do jogo que os designers determinaram antecipadamente. Os chamados 'usuários' lidam com as dificuldades improvisando (ANASTASSAKIS; KUSCHNIR, 2013), ou seja, respondendo na medida em que se confrontam com os objetos.

Ingold (2012) está sugerindo uma maneira diferente de pensar design. Para ele, objetos projetados não determinam o seu uso, pois as pessoas não 'usam' os objetos, eles improvisam na medida em que as dificuldades se apresentam. Os elementos que compõem o café da manhã não são "objetos acabados respondendo a um projeto (design) que precedeu e garantiu sua manufatura" (INGOLD, 2012, p. 30, tradução nossa). Esses objetos são realmente coisas, não terminadas, mas continuadas no uso, como a vida de uma pessoa continua quando senta na mesa para tomar café. Isso tudo quer dizer que quem coloca a mesa e come está designing ${ }^{5}$ o seu café da manhã. Seu papel é atuar como um mediador entre as coisas. Até que tudo esteja colocado, não se pode dizer com precisão para que serve cada item. Isso vai de encontro à teoria do "design centrado no usuário" que coloca os 'usuários' como meros consumidores de objetos criados para eles, e não por eles (INGOLD, 2013).

Nestes termos, os membros do coletivo Santa sem Violência eram praticantes habilidosos. Não se guiavam por regras e iam aprendendo no caminho. Seus processos eram improvisatórios e resultavam da destreza de saber manejar a incerteza e de não considerar as funções prévias das coisas. Igualmente, as ruas e praças são coisas em constante transformação, continuadas no 'uso', e não objetos terminados. Ingold (2012) se pergunta: "como os designers podem passar de conceber soluções que restrinjam os praticantes a jogar por meio de suas próprias regras, a uma posição na qual essas regras estejam abertas à negociação e em que as intervenções improvisatórias dos praticantes apresentem uma oportunidade e não uma ameaça?" (INGOLD, 2012, p. 32, tradução nossa) Ele considera que esta e outras questões são centrais para Design Anthropology (DA) (INGOLD, 2012, p.32).

\footnotetext{
${ }^{5}$ Esta palavra não tem tradução exata para o português, porque não é uma ação antecipada de "projetar". Ingold (2012) considera que o chamado uso é uma extensão do que chamamos de projeto, ou seja, ele inclui o uso no processo de design. Por isso o autor diz que quando uma pessoa senta à mesa e come, ele também está "projetando".
} 
Como foi mencionado anteriormente, DA é um campo em movimento e contínua transformação que conjuga elementos do design e da antropologia com o intuito de construir um terceiro espaço. Um ponto de encontro entre o design e a antropologia tem sido a etnografia. Wasson (2000), Clarke (2018) e outros autores mostram como, desde os anos 1980, antropólogos têm participado de processos de design produzindo etnografias que depois eram incorporadas ao trabalho designers, como insumos ao desenvolvimento de produtos. Esta relação em que a antropologia cria recursos para o design, ainda que válida, tem sido repensada por designers e antropólogos. A coletânea Design Anthropology - Object Cultures in Transition, Alison Clarke (2018) afirma que a antropologia como uma disciplina 'aplicada' ao design tem se dissipado, dando lugar a uma prática conjunta, que se pergunta como a humanidade poderia ser (re)imaginada. Considerando que os membros do CSSV eram praticantes habilidosos, que DA conjuga elementos do design e da antropologia e que se propõe a reimaginar o mundo, pode-se dizer que esta pesquisa se enfoca na colaboração. Como designer e pesquisadora, eu não pretendia fazer um estudo dos habitantes de Santa Teresa para depois desenvolver um produto direcionado a este público. Eu me uni ao coletivo para construir alternativas para o futuro colaborativamente.

Para Gunn e Donovan (2012), a antropologia pode aprender a partir do design como reunir as pessoas (draws people together), pois as ferramentas dos designers tornam possíveis relações sociais. Já Kjærsgaard et al (2016) afirmam que, em DA, a colaboração é um aspecto presente tanto no design como na antropologia. Os autores identificam que a colaboração e a participação entre diferentes stakeholders têm se tornado ponto de convergência nas duas áreas.

Como designer e pesquisadora, não fui eu quem trouxe espaços de colaboração e discussão para o coletivo, ao contrário de projetos de design, em que a colaboração é um eixo central. A colaboração foi fundamental para o grupo desde o primeiro convite para conversar com moradores no Largo das Neves, e minha postura foi tentar respeitar esta condição através da correspondência ${ }^{6}$ e da atenção a acontecimentos emergentes. Além disso, eu não tinha um briefing a ser seguido. Assim, como propõem Kjærsgaard et al (2016), no trabalho com o coletivo desenvolveram-se ferramentas para a investigação de fenômenos emergentes e indeterminados.

Como designer e pesquisadora, tal como sugere o antropólogo dinamarquês Joachim Halse (2010), ultrapassei os muros da universidade e abandonei a ideia de que o estúdio de design é um lugar privilegiado para a invenção. Levar o estúdio de design para o bairro de Santa Teresa significou não só a imersão em situações da vida real, senão a aceitação de que as necessidades não estão prontas esperando que uma designer ou antropóloga competente as descubra. As necessidades estão em contínua formação, e como Halse (2010) sugere, é através do engajamento nas contestações da vida cotidiana que nos colocamos em sintonia com elas. Deslocar o estúdio de design também implicou assumir que a inovação não surge só de lugares privilegiados. Como apontam Kjærsgaard et al (2016), do ponto de vista de DA, os futuros não são entendidos como visões surpreendentes criadas por cientistas ou designers, senão como explorações colaborativas de possibilidades, formações e ações situadas na intersecção do design com a vida cotidiana. Estes autores reiteram as capacidades de inovação e criatividade entre pessoas comuns em seus ambientes do dia-a-dia.

Nas quatro coletâneas de DA, é possível perceber que há uma preocupação com o tempo. Nestes livros, mostra-se que os praticantes de DA estão preocupados com os fenômenos emergentes e com as relações entre passados, presentes e futuros. Segundo Otto e Smith (2013), um desafio de DA é ampliar o horizonte temporal e ancorar imagens do futuro em construções confiáveis do passado,

\footnotetext{
${ }^{6}$ Correspondência é um termo cunhado pelo antropólogo britânico Tim Ingold. Ele aponta que corresponder com o mundo "não é descrevê-lo ou representá-lo, mas responder a ele". (GATT; INGOLD, 2013, p. 144).
} 
evitando o risco de desfuturização (Fry, 2010), que, por vezes, é inerente ao design moderno. No coletivo, houve momentos em que o grupo se preocupou em ancorar imagens do futuro em construções do passado. As teorias do antropólogo Hirokazu Miyazaki ${ }^{7}$ permitem perceber como os momentos de esperança no passado conduzem a novos momentos de prospectividade. Trazer o passado ao presente desequilibra o entendimento linear do tempo, que segundo Kjærsgaard et al (2016), é questionado por DA.

Para estes autores, o futuro não é um lugar vazio e separado; passados, presentes e futuros estão intimamente ligados e mutuamente constituídos. O futuro nasce de nossa vida cotidiana e é múltiplo. Segundo Kjærsgaard et al (2016), os praticantes de DA devem compreender o futuro como uma multiplicidade de ideias, críticas e potencialidades. Pode-se ver este tipo de espaço no CSSV, pois era um grupo aberto a diálogos com a comunidade. No entanto, o coletivo não foi constantemente assim. Em meio ao diálogo haviam restrições às diferenças. Em uma das primeiras reuniões do grupo, pensando em como lidar com a violência, cada um dos participantes trouxe visões de como abordar o problema. Foi difícil chegar a um solução que todos concordassem. Inclusive, dois dos membros do coletivo deixaram de assistir às reuniões, suponho porque não aprovaram as idéias do grupo e a forma com que estávamos lidando com a situação.

Em várias circunstâncias, membros do núcleo excluiram outros membros das redes sociais porque não concordavam com as atividades que o grupo estava desenvolvendo. É complexo trabalhar com a diferença, porém, como afirmam DiSalvo (2010) e outros autores, o pluralismo agonístico é fundamental para a democracia, pois evita o apagamento da diferença. Uma das aprendizagens da experiência com o coletivo é que lidar com friç̧ões não é uma tarefa simples.

Por último, em DA, a intervenção é uma forma de fazer pesquisa. Para Otto e Smith (2013), uma contribuição do design a DA é o desenvolvimento de métodos que empregam diferentes tipos de intervenção. Estes autores explicam que DA está mais orientado à intervenção do que a antropologia tem estado tradicionalmente. Para estes autores, alguns pesquisadores da antropologia têm pavimentado o caminho para uma etnografia intencionalmente intervencionista. As abordagens intervencionistas criam um novo paradigma que dá peso à capacidade humana de mudança por meio de um design intencional.

Na quarta coletânea, Design Anthropological Futures, Kjærsgaard et al (2016) afirmam que "a intervenção é cada vez mais utilizada como método de pesquisa-ação, permitindo o surgimento de novas formas de experiência, conscientização e diálogo" (KJ/ERSGAARD et al, 2016, p. 6, tradução nossa). Neste livro, o termo 'especulação intervencionista' é usado para destacar abordagens que usam a especulação e a transformação para fazer pesquisa.

A pesquisa com o coletivo foi intencionalmente intervencionista e especulativa. Intervencionista, porque, como pesquisadora, eu trouxe propostas para modificar a realidade e participei das ações do grupo. Minha postura com o coletivo foi mais de participante do que de que observadora, embora meu papel se localize no meio dessas atitudes. Como intervenções posso citar a oficina de cartazes, todos os artefatos que produzimos para engajar as pessoas no bairro e comunicar ideias do coletivo, as ações realizadas nas ruas e nas praças, as reuniões, os convites à comunidade etc.

Por outro lado, a pesquisa foi especulativa porque, como grupo, (re)imaginamos o futuro e indagamos sobre alternativas para escapar da violência que nos afetava diretamente. Especular implica em lidar com a incerteza e avaliar os recursos disponíveis. Houve vários momentos de

\footnotetext{
${ }^{7}$ Hirokazu Miyazaki é um antropólogo japonês, professor da Northwestern University no Estado de Illinois, Estados Unidos. Um dos seus interesses de pesquisa é como manter viva a esperança. Para mais informação ver IBARRA, 2018.
} 
especulação, como a oficina de cartazes, as reuniões em que criamos o estêncil e planejamos a manifestação, a reunião em que apresentamos os resultados de uma pesquisa rápida de como outros bairros tinham lidado com a violência, a reunião em que nasceu a ideia de pintar escadarias etc. A especulação fez com que se desequilibrasse o futuro hegemônico que outros organismos (o governo, a polícia, entre outros) estavam impondo para o bairro e para os moradores. Assim, a especulação se torna uma ferramenta para pensar diferentes alternativas e criar futuros múltiplos.

A partir do que foi discutido nesta seção, percebe-se as características da conjunção entre design e antropologia que estão presentes nesta pesquisa.

\section{Considerações finais}

Na aproximação do design e da antropologia que propõe o campo de DA, encontrei o estímulo para despertar uma sensibilidade que me permitiu experimentar um design que, como aponta Clarke (2011), responde socialmente.

Reconhecer que os chamados usuários não são passivos e que o processo de design não é fechado a propósitos preestabelecidos abre novas possibilidades para o design como disciplina. Os designers não só resolvemos problemas. Nosso papel no mundo, pode ser também, facilitar o processo de determinação de problemas e de provocar debates sobre a cotidianidade, muitas vezes subestimada. Para isso, saímos do estúdio de design e nos colocamos em sintonia com as contestações do dia-a-dia. Nessa direção, o design pode ser uma prática mais interpretativa e especulativa.

A antropologia junto com o design, conduz a uma prática antropológica menos descritiva e mais intervencionista. O design junto com a antropologia, conduz a uma prática mais sensível, atenta e colaborativa.

O engajamento com o CSSV, trouxe reflexões relacionadas com a ampliação do horizonte temporal do design, sobre o ideal de progresso e desenvolvimento, sobre a improvisação em processos de design, sobre o domínio do ser humano sobre a natureza, sobre a exploração colaborativa de futuros possíveis etc. Reflexões e pesquisas, sob a perspectiva de DA, estão tendo lugar em alguns laboratórios e universidades do Brasil. Por exemplo, nas teses e dissertações do Laboratório de Design e Antropologia da ESDI/UERJ liderado por Zoy Anastassakis e Barbara Szaniecki, e no Núcleo de pesquisas em Inovação, Design e Antropologia - NiDA da Universidade Federal de Maranhão, coordenado por Raquel Noronha. Alguns projetos relacionados ao tema têm sido desenvolvidos na USP, por exemplo, a dissertação de mestrado de Bruna Montuori e na PUC-Rio, com a dissertação de mestrado de Lorena Otero. Até o fechamento deste artigo, a Revista Arcos da ESDI/UERJ estava preparando o dossiê "Correspondências entre design e antropologia", editado pelas

professoras Zoy Anastassakis e Raquel Noronha, com textos de pesquisadores nacionais e internacionais.

\section{Referências}

ANASTASSAKIS, Z.; KUSHNIR, E. Trazendo o design de volta á vida: considerações antropologicamente informadas sobre as implicações sociais do design. In: Guilherme de Cunha Lima; Lígia Medeiros (orgs.). Textos selecionados de design 41 ed. Rio de Janeiro: PPDESDI/UERJ, p. 137-141, 2013.

CLARKE, Alison J. (Ed.). Design Anthropology. Object culture in the 21st Century. Viena: SpringerVerlag, 2011. 
DISALVO, C. Adversarial Design. Cambridge, Mass: MIT Press, 2012

ESCOBAR, A. Autonomía y diseño: La realización de lo comunal / Arturo Escobar. --Popayán: Universidad del Cauca. Sello Editorial, 2016.

GUNN, W; DONOVAN, J. Design Anthropology: An Introduction In: GUNN, W; DONOVAN, J. (Eds.). Design and Anthropology. London: Ashgate, 2012. p. 1- 19

GUNN W; OTTO T; SMITH R C. Design Anthropology: Theory and Practice. London: Bloomsbury, 2013.

HALSE, J. Manifesto/Introduction. In: HALSE, Joachim, BRANDT, Eva, CLARK, Brendon, and BINDER, Thomas. Rehearsing the Future, 2010. p. 10-17

IBARRA, M. Entrelaçando design com antropologia: Engajamentos com um coletivo de moradores do bairro de Santa Teresa no Rio de Janeiro. Tese (Doutorado em Design) - Escola Superior de Desenho Industrial, Universidade do Estado do Rio de Janeiro, p. 237. 2018

INGOLD, T. The Perception of the User-Producer In: GUNN, W; DONOVAN, J. (Eds.). Design and Anthropology. London: Ashgate, 2012. p. 19-34

KJAERSGAARD, M; HALSE, J; SMITH, R; VANGKILDE; K, BINDER, T, OTTO, T. Introduction: Design Anthropological Future. In: SMITH, Rachel Charlotte, VANGKILDE, Kasper Tang, KJ/ERSGAARD, Mette Gislev, OTTO, Ton, HALSE, Joachim, and BINDER, Thomas. Design Anthropological Futures, 2016. p. 116.

MOGENSEN, P. Towards a Provotyping Approach in Systems Development. Scandinavian Journal of Information Systems: Vol. 4: Iss. 1, article 5. 1992.

OTTO, T; SMITH, R. Design Anthropology: A Distinct Style of Knowing. In: Gunn W, Otto T, Smith RC, eds. 2013. Design Anthropology: Theory and Practice. London: Bloomsbury. p. 242-274

SERAVALLI; ERIKSEN; HILLGREN. Co-Design in co-production processes: jointly articulating and appropriating infrastructuring and commoning with civil servants. CoDesign International Journal of CoCreation in Design and the Arts, 2017. Disponível em: <https://www.hutskane.nu/wpcontent/uploads/2018/01/171128-Co-Design-in-co-production-processes-jointly-articulating-andappropriating-infrastructuring-and-commoning-with-civil-servants1.pdf> Acesso em: 14 Jan 2018.

SMITH, R; VANGKILDE, K; KJAERSGAARD, M; OTTO, T; HALSE, J; BINDER, T. Design Anthropological Futures, London: Bloomsbury. 2016.

WASSON, C. Ethnography in the Field of Design. In: Human Organization, vol. 59, n. 4. Society for Applied Anthropology, 2000, p. 377-388. 